Editorial

\title{
Sustainability of Rural Tourism and Promotion of Local Development
}

\author{
Antonietta Ivona
}

Citation: Ivona, A. Sustainability of Rural Tourism and Promotion of Local Development. Sustainability 2021, 13, 8854. https://doi.org/ $10.3390 /$ su13168854

Received: 4 August 2021

Accepted: 5 August 2021

Published: 8 August 2021

Publisher's Note: MDPI stays neutral with regard to jurisdictional claims in published maps and institutional affiliations.
Department of Economy and Finance, University of Bari, 70121 Bari, Italy; antonietta.ivona@uniba.it

\section{Introduction}

Since the 1970s but with greater intensity in the 1980s, strong, social, economic, and cultural transformations have led to the post-Fordist or post-productivist countryside determining what researchers identify as "rural restructuring". Evolving from a vision of the rural area as an undifferentiated space for the vast production of food, people now consider it a space with different functions-naturalization, residency, landscape and environment, and historical and cultural memory-that complement or even replace production as well as a space with many economic, social, and ecological dynamics; these functions differ from one territory to another [1].

In recent years, the rural world has undergone new changes. Nature conservation and local culture have become increasingly important. Historic buildings and traditional rural societies have received more attention. Some rural regions that are more accessible than others have been repopulated with the arrival of those who have left the city (counter-urbanization). However, for many rural areas, the declining trend remains. The contemporary literature suggests two concepts to describe the current processes: multifunctionality and diversification, both relating to the individual farm and to the territorial system examined [2,3].

The first concept of multifunctionality refers to the various functions performed by the agricultural sector that are placed side by side against the "traditional" with the production of goods made for the market (mainly food but also fibers, timber, and other products). Until twenty years ago, public intervention in support of the agricultural sector was responsible for the maintenance of employment and the regulation of migration flows from rural to urban areas; currently, privileged aspects of environmental care and overall quality of life are attributable to the following categories: revitalization and socioeconomic development of rural areas, food variety understood as the availability of a plurality of different products to limit the increasing standardization of food imposed by the industrialization and globalization of models of production and consumption, and maintenance and reproduction of the physical and anthropic environment. These new features, however, cannot be separated from traditional farming, but they derive from the complex relationships between agricultural production, nature, and the human environment in which the production takes place.

The second abovementioned concept is diversification related to the coexistence of traditional agricultural activity together with industrial, handicraft, tourist and recreational, nature protection, and residential activities. Diversification plays an important role in formulating the policies of agricultural and rural areas in consideration of the opportunities for income and employment (and its induced effects) that may result and that may partly offset the reduction in income derived from the exercise of traditional agricultural activities. Diversification can also represent a mode of remuneration of some of the production processes, and thus, multifunctionalities can contribute to their reproduction and maintenance over time.

The growing complexification of rural tourism is reflected in its possible definitions according to accommodation, location, activities, interest, or motivations. It is considered 
opposite to urban tourism, referring to a certain form of tourism realized in a different, unusual place. Taking into account all of the different considerations and research, it is not easy to give a unique global definition. Generally, rural tourism activity is endowed with some uniqueness, as it takes place in rural areas and the main motivation is the pursuit of tourist attractions associated with relaxation, the countryside, traditional culture, and escape from the maddening crowd. A further definition considers rural tourism as "that tourist activity in rural areas, structured by an integrated offer of leisure, and directed to a reasoned request through contact with the native environment and with a relationship with local society" [4].

\section{Rural Tourism}

Rural communities see the development of tourism as an opportunity to diversify the economy of rural areas and to revitalize territories that are otherwise no longer competitive in the face of market dynamics and the evolution of agricultural policies. The interest in tourism as a factor in the development of rural areas lies in numerous elements, real or presumed, such as the need for high work and easily acquired preparation, that are therefore able to guarantee high involvement of the local population, especially in females and female groups, youth, the possibility for local actors to start new activities with even limited private investments but also to attract investment flows from outside, and the activation of a demand capable of creating induced and therefore extended activation effects on a multiplicity of economic locals activities [5-7]. In the framework outlined, the territory assumes multiple economic and social values. In this way, it becomes a stage and actor, at the same time, of those economic activities that propel a new development that is much more aware and lasting than in the past.

Rural tourism has been considered, therefore, as a chance to promote local development, thus representing an economic activity that involves a change in rural areas. Consequently, marketing activities begin to play a very important role, and selling rural tourism means selling activities in a rural space (for instance, walking, climbing, hunting, adventure, sport and health tourism, educational travel, arts, and heritage), thus showing its main facets. This is an economic activity with potential social, economic, and environmental impacts that are highly dependent on the local characteristics of a region, and it has the potential to stimulate rural economies with positive effects on farm income. However, the extent of the financial benefits and economic impact is still contested due to conservative estimates.

One of the priorities of rural tourism development is, thus, its sustainability; according to the World Tourism Organization: "Sustainable rural tourism is to find the correct harmony in the relationship established between the needs of the visitor, the place and the receiving community". Therefore, the main functions of rural tourism are the following: completing agriculture, recovering the traditional architectural heritage, managing natural and cultural resources, and promoting the integration of the local population into tourism to improve their quality of life [8-10]. Furthermore, rural tourism should generate additional revenue, contribute to the economic revitalization of depressed areas, promote the maintenance of agriculture, and incorporate women in paid work.

Besides the complexity of rural tourism definitions, rural tourism is perceived differently in different countries. For example, rural tourism products are often based on bed and breakfast, with accommodation in traditionally furnished rooms and traditional breakfasts often based on home-made products as in Greece, for example. In Finland, rural tourists usually rent out cottages. In the Netherlands, rural tourism products mean camping on a farm and route-bound activities such as walking, cycling, or horseback riding. In Hungary, rural tourism has a special term: village tourism, which refers to tourism in villages, presenting life in the country plus traditions with the active participation of visitors [11]. 


\section{The Many Ways for Local Tourism Development}

A systematic review of the scientific literature of the sector can be very useful for understanding the many facets of the delicate balance between economic development and rural tourism; the different perspectives on the basis of which the scientific literature deals with the theme of rural tourism indicate the possible tools to support the sustainable development of rural areas. The current trends show how rural tourism represents a growing market that offers rural communities an interesting opportunity for growth. More and more tourists pay attention to the values of culture, food, and landscape. Furthermore, it can make a valuable contribution to the sustainable development of rural areas. To this end, the organization of agricultural businesses also evolves towards alternative network models that guarantee greater economic and social benefits and a renewed active role in the agri-food system.

These models are characterized by a reconnection between producers and consumers with these explicit ethical and political objectives: revitalization of the identity of the territory and the relations of the rural community with food and local agriculture, the link with agricultural sustainability, and economically sustainable and socially responsible practices.

The new demand for rurality, therefore, raises new questions: it is no longer a question of perpetrating a traditional agricultural model based solely on productivity and profit maximization but rather an agriculture strongly oriented towards multifunctionality that also involves peri-urban areas. An example could be agricultural parks, innovative and multifunctional, where agriculture is practiced with environmental, landscape, and social functions; they could represent, in the near future, a strategic resource for the tourist enhancement of peri-urban areas. In this perspective, two Italian case studies, the Ciaculli Agricultural Park (Sicily) and the Agricultural Park Sud Milano (Lombardy), are examples of how agricultural parks can play the role of drivers for tourism development. The first is the last extensive agricultural area in the municipality of Palermo. The park was created starting from the elements of the historically formed agricultural system, highlighting their role in defining the specific overall relationships and their degree of persistence, and planning interventions for the conservation, recovery, restoration, or replacement based on their intrinsic value of architectural and environmental assets. The entire area was affected by interventions to safeguard the traditional functions of peri-urban agricultural activity, in particular, the productive function since the best protection of territory is achieved by assigning or maintaining compatible uses. An important element in the realization of the park was the participation and sharing of the entire process with the local players because it had the merit of intervening in an area and a sector in economic crisis, giving a response that contained as many elements of revitalization as possible. The Agricultural Park Sud Milano covers about 30\% of the total surface area of the Metropolitan City of Milan. The aims of the park are to protect and restore the landscape and environment of the strips linking the city and the countryside; to connect the external areas with the urban green systems; to balance the ecology of the metropolitan area; and to safeguard, qualify, and develop agro-silvicultural activities and cultural and recreational use.

In both cases mentioned, agriculture is the driving activity chosen to preserve agricultural territories, enhancing the different crops present historically. Multifunctional agriculture is carried out through the activation of various services: food production, catering, direct sales, accommodation, environmental education, environmental services, maintenance of the landscape and biodiversity, sporting activities, and organization of rural tourist itineraries.

Of particular interest in this type of relationship is the portion of land in contact with the two areas or, rather, at the border of both, where one ends and the other begins; "urban" and "rural" are not entities that exist independently of human practice and special interests: rather, the nature and character of these categories depend on how they are defined. Therefore, it is important to reflect on the type of relationship between the two 
areas or, rather, on the border of both, where one ends and the other begins, to define the best possible interaction.

While recognizing the limits of peri-urban agriculture such as greater demographic pressure in these contexts and greater competition on the use of natural resources, however, this type of agriculture can count on other positive aspects such as proximity to local markets and economic and social dynamism compared with traditional rural areas.

The tools for tourism development in rural areas are varied and very heterogeneous. As in the case of regional parks where the social dimension plays an essential role also for the revitalization of rural villages, this role is fundamental. Territorial identity can constitute the theoretical foundation to influence development policies and, in particular, tourism development for the sustainability process. This strong depopulation has caused a loss of skilled labor and businesses, causing both economic and socio-environmental degradation. As the geographic literature shows, there are three possible remedies historically followed: The first is the so-called "conservative" approach, which suggested maintaining a minimum level of services for the population to discourage further abandonment. The second "compensatory" approach envisaged a sort of replacement of new residents who would compensate for the abandonments. Finally, the third "multifunctional" approach is derived from the superimposition of the concepts of inland areas and rurality, both expressions of territorial marginality. However, all three approaches have not stopped the depopulation of these territories and their small villages.

The revitalization process of these territories takes a long time due to current conditions; at the same time, tourism today requires the rediscovery of values such as the conservation and authenticity of their tangible and intangible cultural heritage, achievable through different cultural and social factors (identity, traditions, memories, intangible ties, local peculiarities, and rural landscapes). Most of these municipalities have been identified in Italy and are so-called "borghi", characterized by a maximum of 5000 inhabitants and "from a precious cultural heritage, whose conservation and enhancement are factors of great importance for the country system as they represent authenticity, uniqueness and beauty as distinctive elements of the Italian tourist offer" (Directive n. 555/216 of the Italian Ministry of Cultural Heritage and Cultural Activities and Tourism). Today, they constitute the backbone of Italy, covering a territorial surface of about $54 \%$ of its total territorial surface and, in some regions, reaching even $70-80 \%$ of the total regional surface. This expanse of surface does not correspond to the anthropic aspect since the resident population is $17 \%$ of the total Italian population, and in some regions, this average percentage still drops compared with the regional resident population.

Many of these towns are characterized by a rural landscape, and many others are located in the mountains or on the coasts. However, all of these are very different in their resources and heritage, which are rich in content, interconnected, and integrated, and, together with their strong anthropological characteristics, refer to the culture and lifestyles of the settled communities.

The territorial identity becomes substantial in the definition of the "borghi", and the community is a fundamental part of it as it combines the historical characteristics of the territory with the innovative ones. A place to develop tourism always safeguards the territory, understood in its human, historical, architectural, natural, landscape, cultural, social, and economic meaning. Furthermore, to highlight the tourist value of the "villages", their tourist vocation should also be considered. The recovery of the "borghi" for tourism purposes, therefore, can be undertaken only if it forms a territorial identity capable of reviving an active and dynamic community, both to activate that sense of uniqueness of places, the genius loci, and the narrative of cultural heritage.

An interesting example of the enhancement of the "borghi" is that of the rural area of the "Monti Dauni" in Apulia (in Southern Italy). Within these small towns, following the consolidated principles of sustainability and social cohesion, local actors aim to maximize the opportunities for sustainable and experiential tourism by offering an uncontaminated environment, ancient knowledge, genuine flavors, and deep emotions to all visitors who 
wish to deepen their knowledge of the territorial identity instead of being mere spectators, adopting an active and committed attitude. Thus, the communities can become key players of a real "hot authentication" path according to the definition given by E. Cohen and S.A. Cohen [12] of their milieu, initiating a "recreational re-ruralisation" [13] (p. 206) that catches the interest of travelers in search of "a break to replenish energies and regenerate" [14] (p. 20), creating "unprecedented forms of economy and socialization and building newancient meeting places" (Ibidem).

In the town of Mértola (Portugal), a peripheral territory with fewer opportunities and a structural crisis, historical heritage of the town, its conservation, and its value of tourism have been converted into a comparative advantage that generates opportunities for local development. However, the substantial amount of heritage increases its conservation costs and hinders the continuity of conservation projects. The social, political, and institutional contexts define the processes of heritagization and its value for tourism, which generate the dialectic between heritagization and the exploitation or the commodification of heritage as well as its overall perceptions and the conceptions of development that are significantly dependent on dominant relationships and discourses. First, the cooperation and then the competition between private and public actors indicate contradictions and conflicts. The recovery of the collaborative approach improves the results that are reflected by the increase in tourist supply and demand.

Today, the sustainability of rural tourism development appears as a multi-faceted issue; it involves not only traditionally inland areas but also coastal areas. The case of the Delta of Nemunas and Laguna dei Curi (Lithuania) is, in fact, an example: through the integration of tourist activities with those historically carried out, the local population has the opportunity (a potential supply of cultural ecosystems) to realize the diversification of economic activities to meet the needs of tourists (a potential demand for cultural ecosystems) to achieve service differentiation. Even the Luoshan Organic Agriculture village in Taiwan can be an example, focusing on organic farming and cultivation. The village was developed through community empowerment and the utilization of existing tourism resources. The integration between natural resources of the landscape and the experience of organic farming has contributed to the success of this travel destination. Here, the uniqueness of organic farming and the image of environmentally conscious tourism have merged to convey a positive image on the tourist market.

From a strategic point of view, it can certainly be said that rural and sustainable tourism development is the result of a skillful combination of several elements present in the area. The rural area of Marginimea Sibiului in Romania has managed to achieve national and international notoriety by developing consistently, capitalizing on its natural and cultural heritage and providing services in successful farms and rural guesthouses, which have continuously evolved both numerically and in terms of comfort levels.

Cultural heritage is a vital part of a society's existence. The real challenge is between cultural conservation and economic development in general. Twenty-first century China faces this in its race for economic development. Two case studies, from Lijiang in Yunnan province and Rizhao in Shandong province, demonstrate how a successful tourism strategy generates many cultural benefits while minimizing costs for the host community.

The implementation of sustainable rural tourism through "best practices" allows for diversification of the offer and for obtaining satisfactory results; through downshifting and permaculture practices, the Brasov region, one of the most important tourist areas in Romania, has created a tourism product in balance with nature, with care for people, and with an ecological lifestyle.

According to the Countryside Commission [15], sustainability is one of the priorities of rural tourism development: "sustainable rural tourism consists in finding the correct harmony in the relationship established between the needs of the visitor, the place and the receiving community". In addition, gender equality is explicitly listed in the 17 Sustainable Development Goals [16]; therefore, looking to the future, the desired harmony should be conceived as social and relational sustainability, meant as a formula to ensure equal gender 
treatment and representation of spatial discourses that ensure visibility, as is the case of gendered cinematic representations that mainly occur in the rural space of the Camino de Santiago (Spain).

The territorial reconfiguration process that led to new uses of agricultural land also have to take into account equally new conflicts of use. Increasingly, scholars detect a conflict of use of the land between the hypothesis of persevering in exclusively agricultural activities and the possibility of introducing new activities. Often, however, agriculture is the only activity practiced by a population that is not sufficient to guarantee sufficient income; it is therefore necessary to diversify economic activities. Are sports such as golf a new form of sustainable tourism or a violation of traditional rural vocations? The answer cannot be univocal but varies according to the different territories considered. In some cases, sports do not completely replace traditional agricultural activity but performs a complementary function to it.

\section{Concluding Remarks}

Tourism has shown that it can play a fundamental role in the development of rural areas, offering rural areas the opportunity to diversify their economy and to improve the quality of life of the local population. In this Special Issue, most papers investigated the possible combination of sustainability and the economic and social development of activities related to rural tourism through extant literature reviews and case studies. All papers show that there is not just one method of development but it is their combination that generates positive effects on the territory and on the communities that populate it. This Special Issue, therefore, tries to suggest some ways to implement the principles of sustainability in tourist and rural activities. The case studies can be considered "good practices" to inspire future economic and social development strategies for rural areas.

Funding: This research received no external funding.

Institutional Review Board Statement: Not applicable.

Informed Consent Statement: Not applicable.

Conflicts of Interest: The author declares no conflict of interest.

\section{References}

1. Belletti, G.; Berti, G. Turismo, ruralità e sostenibilità attraverso l'analisi delle configurazioni turistiche. In Aree Rurali e Configurazioni Turistiche. Differenziazione e Sentieri di Sviluppo in Toscana; Pacciani, A., Ed.; Franco Angeli Edizioni: Milan, Italy, 2011.

2. Wilson, G.A. The spatiality of multifunctional agriculture: A human geography perspective. Geoforum 2009, 40, $269-280$. [CrossRef]

3. Saxena, G.; Ilbery, B. Integrated Rural Tourism. A Border Case Study. Ann. Tour. Res. 2008, 35, 233-254. [CrossRef]

4. European Commission. Towards Quality Tourism Rural Urban Costal. 1999. Available online: http:/ / ec.europa.eu/enterprise/ sectors/tourism/files/studies (accessed on 15 May 2021).

5. Ammirato, S.; Felicetti, A.M. The Agritourism as a Means of Sustainable Development for Rural Communities: A Research from the Field. Int. J. Interdiscip. Environ. Stud. 2014, 3, 17-29. [CrossRef]

6. Lane, B. What is rural tourism? J. Sustain. Tourism. 1994, 2, 1-2. [CrossRef]

7. Belletti, G. Ruralità e turismo. Agriregionieuropa 2010, 20, 11-13.

8. López Palomeque, F.; Marchena Gómez, M.; Clavé, S.A.; Vera Rebollo, J.F. Análisis Territorial del Turismo y Planificación de Destinos Turísticos; Tirant lo Blanch: Valencia, Spain, 2011.

9. De Rosa, M.; McElwee, G.; Smith, R. Farm diversification strategies in response to rural policy: A case from rural Italy. Land Use Policy 2019, 81, 291-301. [CrossRef]

10. Ivars Baidal, J.A. Turismo y espacios rurales: Conceptos, filosofías y realidades. Investig. Geogr. 2000, 23, 59-88. [CrossRef]

11. Ayazlar, G.; Reyhan Ayazlar, A.R. Rural Tourism: A Conceptual Approach. In Tourism, Environment and Sustainability; Avcikurt, C., Dinu, M., Hacioğlu, N., Efe, R., Eds.; St. Kliment Ohridski University Press: Sofia, Turkey, 2015.

12. Cohen, E.; Cohen, S.A. Authentication: Hot and Cool. Ann. Tour. Res. 2012, 3, 1295-1314. [CrossRef]

13. Claval, P. Introduzione Alla Geografia Regionale; Zanichelli: Milan, Italy, 1996.

14. Decandia, L. Ripensare la "società dell'azione", e ricominciare a "guardare il cielo": La montagna come "controambiente" del sublime in una inedita partitura urbana. Sci. Territ. 2016, 4, 18-24. 
15. Countryside Commission. Sustainable Rural Tourism: A Guide to Local Opportunities; Countryside Commission: Cheltenhman, UK, 1995.

16. UN. Introduction and Proposed Goals and Targets on Sustainable Development for the Post 2015 Development Agenda; UN: New York, NY, USA, 2014. Available online: https:/ / sustainabledevelopment.un.org/content/documents/4523zerodraft.pdf (accessed on 20 July 2021). 